\title{
MEDIA VISUAL BERBENTUK KATALOG PRODUK SEBAGAI MEDIA PROMOSI
}

\author{
Wahyu Hidayat ${ }^{1}$ \\ Riri Mahmuriyah ${ }^{2}$ \\ Sri Ndayani Ratna Safitri ${ }^{3}$ \\ Dosen STMIK Raharja ${ }^{l}$ \\ STMIK Raharja Tangeran Jurusan Teknik Informatika ${ }^{2,3}$ \\ Jl. Jendral Sudirman No. 40, Modernland, Tangerang \\ e-mail:_wahyu@raharja.info,riri@raharja.info,ratna.safitri@raharja.info
}

\begin{abstract}
ABSTRAK
Ilmu pengetahuan dan teknologi informasi berkembang cukup pesat dan menghasilkan inovasiinovasi baru yang senantiasa terus berubah ke era yang lebih baik. Informasi menjadi kata kunci dalam berbagai aspek kehidupan, siapa yang dapat menguasai informasi, baik pengusaha dalam proses penyajian, maupun pendapatan, ia akan bisa bertahan ditengah persaingan yang sedemikian ketat. Dengan alasan inilah perhatian terhadap proses informasi menjadi sangat ditekankan. Teknologi informasi khususnya teknologi berbasis multimedia diharapkan dapat memberikan peranan penting dalam proses penyaluran informasi, aplikasi multimedia mampu menghasilkan suatu informasi menjadi lebih efektif dan komunikatif.
\end{abstract}

Kata kunci : Promosi, Visual, Multimedia.

\begin{abstract}
Science and information technology is evolving quite rapidly and produce new innovations are constantly changing to a better era. Information into keyword in various aspects of life, who can master the information, whether entrepreneurs in the process of rendering, as well as income, he will be able to survive in the middle of such a tight competition. With this reason attention to process information became very stressed. Information technology multimedia-based technologies in particular are expected to provide an important role in the process of channelling information, multimedia application capable of generating information to be more effective and communicative.
\end{abstract}

Keywords: promotion, Audio Visual, Video Profile.

\section{PENDAHULUAN}

Bentuk aplikasi multimedia yang digunakan adalah media komunikasi visual, yang merupakan sebuah sarana promosi ataupun sosialisasi yang efektif dalam penyampaian kemasyarakat luas. Oleh karena itu pengguna pengguna media komunikasi visual sangat dibutuhkan dalam pengenalan diri sebuah perusahaan atau lembaga. Pemberian informasi merupakan suatu usaha yang dibutuhkan perusahaan karena dengan adanya informasi perusahaan, maka perusahaan akan mendapatkan keuntungan yaitu dikenal secara luas.

PT. Anugerah Duta Pratama adalah perusahaan yang bergerak dibidang produksi helm kulit yang berstandar SNI, beralamat di Jl. Jaya Raya No. 47 Rt.02/09 Cengkareng Barat, Kel. Cengkareng, Kec. Cengkareng, Jakarta Barat 11730. Saat ini, media promosi PT. Anugerah Duta Pratama masih menggunakan media brosur, iklan, dan website. Media tersebut masih dirasakan kurang menarik dan belum cukup praktis. Dengan teknologi multimedia dapat dibuat sebuah media promosi dan informasi dalam bentuk aplikasi offline. 
Media promosi tersebut nantinya diharapkan kegiatan promosi perusahaan menjadi lebih efektif dan efisien serta dapat meningkatkan omset PT. Anugerah Duta Pratama itu sendiri.

Dengan dilakukannya analisa terhadap permasalahan yang ada yaitu kurang lengkapnya informasi mengenai perusahaan ini dan belum terdapatnya catalog produk sebagai media promosi yang interaktif, maka penulis tertarik untuk merancang sebuah karya desain katalog produk, agar customer lebih percaya dan mengetahui lebih detail mengenai segala hal yang berkaitan dengan informasi tentang perusahaan. Serta dapat memudahkan bagian pemasaran dalam memperkenalkan seluruh kapasitas perusahaan dan diharapkan melalui proses perancangan ini dapat meningkatkan omset perusahaan.

\section{RUMUSAN MASALAH}

Dalam menghadapi persaingan yang semakin ketat sekarang ini, dituntut untuk mampu merespon pembacanya dengan lebih baik, lebih cepat dan dapat memuaskan pembaca. Semua itu menuntut penyampaian dan penerimaan data serta informasi yang lebih akurat dan tepat. Begitu juga proses pengambilan keputusan harus dapat dilakukan dengan cepat dan tepat waktu kapanpun dibutuhkan dalam membuat keputusan apapun. Saat ini perkembangan media promosi berkembang sangat pesat. Media yang banyak digunakan saat ini dapat berupa media komunikasi visual. Banyak Perusahaan-perusahaan yang sudah menggunakan media visual sebagai salah satu cara untuk mempromosikan suatu instansi perusahaan. Media visual merupakan media yang paling mudah dipahami dan dimengerti oleh calon Customer, karena di dalamnya terdapat unsur - unsur yang menarik, baik dari segi gambar yang mudah dimengerti dan di pahami.

Permasalahan yang melatar belakangi penelitian ini adalah kurangnya media katalog produk yang digunakan oleh PT. Anugerah Duta Pratama dalam mempromosikan secara keseluruhan apa yang ada dan disediakan oleh PT. Anugerah Duta Pratama, karena dalam melaksanakan suatu promosi masih menggunakan sebuah media promosi berupa media cetak, maka dari itu dibuatlah suatu teknik promosi baru untuk PT. Anugerah Duta Pratama dengan menggunakan Media Katalog Produk agar masyarakat atau customer lebih memahami tentang produk yang ada di PT. Anugerah Duta Pratama.

\section{LANDASAN TEORI}

\section{Konsep Dasar Media}

Media adalah sarana untuk menyampaikan pesan atau informasi kepada publik dengan menggunakan berbagai unsur komunikasi grafis seperti teks, gambar atau foto.

\section{Konsep Dasar Desain \\ Pengertian Desain}

Desain merupakan art direction, yaitu penampilan visual secara menyeluruh dari iklan. Hasil kerja sama antara art direction dan copy writer (berupa konsep verbal dan visual) dipadukan secara sinergis kedalam desain melalui proses standar, yaitu membuat sketsa-sketsa kasar, menentukan alternative desain hingga final art work $(F A W)$.

\section{Konsep Dasar Komunikasi Visual}

Desain grafis belakangan lebih sering disebut "Desain Komunikasi Visual" (DKV) karena memiliki peran mengomunikasikan pesan atau informasi kepada pembaca dengan berbagai kekuatan visual, seperti tipografi, ilustrasi warna, garis, layout dan sebagainya dengan bantuan teknologi. 


\section{Definisi Katalog Produk}

Produk adalah segala sesuatu yang dapat ditawarkan untuk diperhatikan, dimiliki, digunakan, atau dikonsumsi yang dapat memuaskan keinginan dan kebutuhan. Produk mencakup objek fisik, jasa, orang, tempat, organisasi dan gagasan.

\section{Fungsi Katalog Produk}

Berikut beberapa fungsi katalog produk, diantaranya :

1. Untuk menawarkan atau menjual barang atau produk.

2. Sebagai alat yang efektif dan efisien.

3. Untuk menekan atau efisiensi biaya penjualan.

4. Sebagai alat memotivasi agen penjualan yang ampuh.

\section{Konsep Dasar Promosi}

Promosi adalah suatu bentuk komunikasi pemasaran. Yang dimaksud dengan komunikasi pemasaran adalah aktivitas pemasaran yang berusaha menyebarkan informasi, mempengaruhi atau membujuk dan mengingatkan pasar sasaran atas perusahaan dan produknya agar bersedia menerima dan loyal pada produk yang ditawarkan perusahaan yang bersangkutan.

Promosi adalah suatu bentuk kegiatan yang diselenggarakan oleh pihak pemasar yang bertujuan untuk menarik perhatian masyarakat, sehingga tertarik untuk melakukan transaksi seperti yang diinginkan oleh pihak pemasar, agar pelaksanaan program promosi dapat berjalan dengan baik, dan segala sesuatunya harus dipersiapkan dengan matang.

Dari kutipan di atas peneliti menyimpulkan bahwa promosi merupakan rangkaian kegiatan pemasaran yang bertujuan untuk memperkenalkan produk yang dihasilkan oleh produsen melalui jalinan komunikasi dengan maksud mempengaruhi dan mendorong konsumen untuk memberi produk yang ditawarkan. Kegiatan promosi dapat dilakukan langsung bertatap muka dengan calon konsumen (personal selling) atau dengan menggunakan media yang ada seperti media massa maupun elektronik.

\section{Konsep Dasar Informasi}

Informasi (information) dapat didefinisikan sebagai berikut : "Informasi adalah data yang diolah menjadi bentuk yang lebih berguna dan lebih berarti bagi yang menerimannya, informasi disebut juga data yang diproses atau data yang memiliki arti”.

\section{Program Aplikasi Penunjang Desain \\ Adobe Photoshop CS6}

Adobe Photoshop merupakan program tercanggih dan terpopuler saat ini ditujukan untuk menyunting dan memanipulasi gambar (image-editing). Program aplikasi ini banyak membantu para professional dalam dunia fotografi, pracetak, dan multimedia.

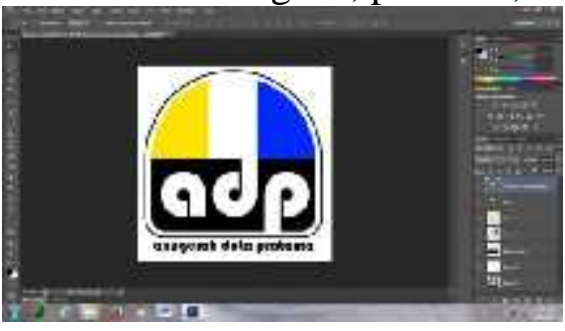

Gambar 1

Tampilan Area Kerja Adobe Photoshop CS6 


\section{CorelDRAW}

CorelDraw adalah sebagai dasar pemahaman seni menggambar di komputer, yang lebih menekankan pada teknik penggunaan fasilitas dasar pada software berbasis CAD (Computer Aided Design)

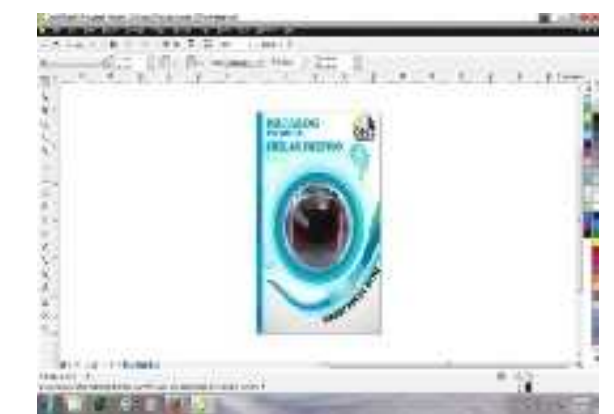

\section{Gambar 2}

Tampilan Area Kerja Corel Draw.

\section{Konsep Desain}

\section{Perencanaan Media}

Dalam hal ini, konsep media yang diajukan adalah perancangan media informasi dan promosi dalam bentuk sebuah desain katalog produk yang berukuran 21 x $29.7 \mathrm{~cm}$. Buku ini berisi cover depan, daftar isi, produk yang ada di katalog, promo terbaru, layanan kami dan our store, our stock daftar our activity, dan cover belakang. Semua isi yang terkait dalam perancangan desain katalog produk tersebut dikemas dengan menggunakan pengembangan kreatif desain grafis.

\section{Strategi Media}

Dalam menunjang nilai efektifitas sarana media yang dirancang strategi media promosi adalah dengan menggunakan bentuk media desain katalog produk, secara visual orientasi gambar-gambar tampilan dengan menggunakan teknik drawing yang diproduksi melalui aplikasi penunjang gambar vektor, hal tersebut secara visual untuk memenuhi 3 aspek sasaran yaitu:

1. Geografi : Dalam dan luar Kota Jakarta

2. Demografi :
a. Jenis Kelamin : Pria \& Wanita
b. Kelas Ekonomi :Umum (mencakup seluruh kelas ekonomi)
c. Sasaran
: Konsumen individu atau perusahaan

3. Psikografi : Bagi konsumen khususnya yang memerlukan produk helem.

\section{Perencanaan Pesan (Konsep Kreatif)}

Rancangan media yang direncanakan menampilkan sesuatu yang baru dan unik yaitu bergaya desain pop art yang lebih menonjolkan pada eksplorasi warna yang ramai, Serta diperjelas dengan teks-teks dan layout yang simple penjelasan secara sepintas, tampilantampilan pesan secara kreatif akan diolah, ditata sesuai dengan kebutuhan pesan yang direncanakan oleh pihak perusahaan.

\section{Perencanaan Visual}

Penyajian desain desain katalog produk dengan tetap mempertahankan warna-warna yang melambangkan identitas logo perusahaan yang diolah dengan menggunakan kombinasi warna lain yang senada dengan warna aslinya. Untuk gambar, penulis menggunakan gambar dari browsing di internet seperti logo mitra kerja PT. Anugerah Duta Pratama dan foto-foto 
yang diambil oleh penulis sendiri dan diolah dengan menggunakan gabungan beberapa software pendukung yaitu Adobe Photoshop dan Corel Draw.

Proses Desain (Designing)

Layout Kasar Cover Depan

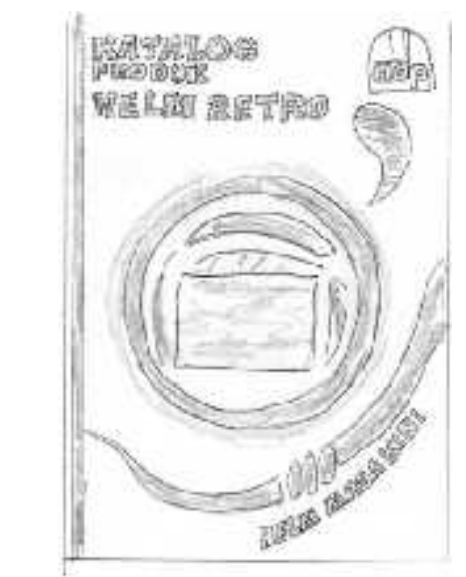

Gambar 3

Layout Kasar Cover Depan

Cover Headline pada promosi ini menggunakan kata : "KATALOG PRODUK HELM RETRO BERGAYA MASA KINI" dengan isi tulisan judulnya berwarna biru sedangkan PT. Anugerah Duta Pratama berwarna hitam. Font yang digunakan pada halaman ini adalah Revisal Bold, Regular, Ultra thin dan hairline.

\section{Layout Kasar Daftar Isi}

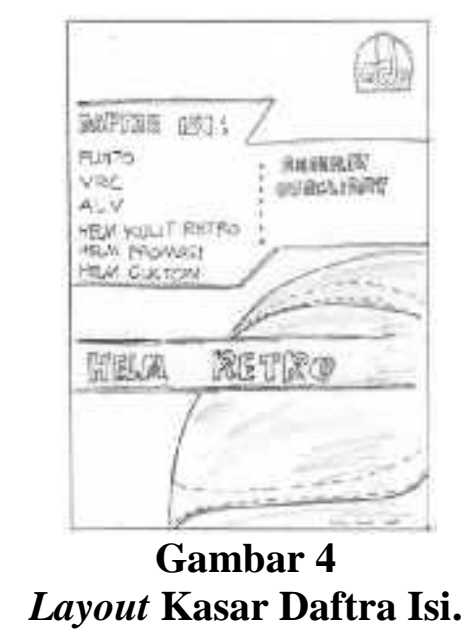

Halaman daftar isi berisi foto produk dengan tata letak atau layout yang menarik dan font yang digunakan dalam halaman ini adalah Revisal dan Minion Pro. 


\section{Layout Kasar Halaman 1}

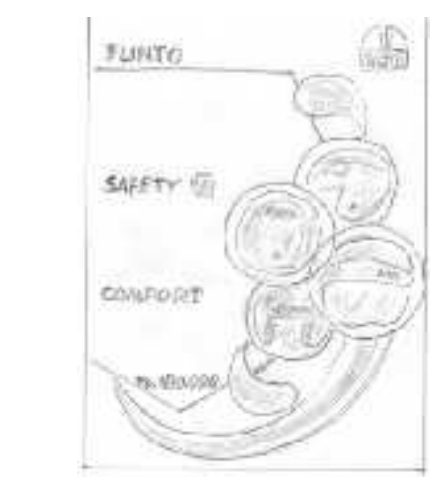

\section{Gambar 5}

Layout Kasar Halaman 1

Halaman 1 berisi foto satu brand dari perusahaan yaitu FLINTO serta menjelaskan keunggulan yang dimiliki salah satu brand perusahaan ini. Font yang digunakan dalam halaman ini adalah Revisal.

\section{Layout Kasar Halaman 2}

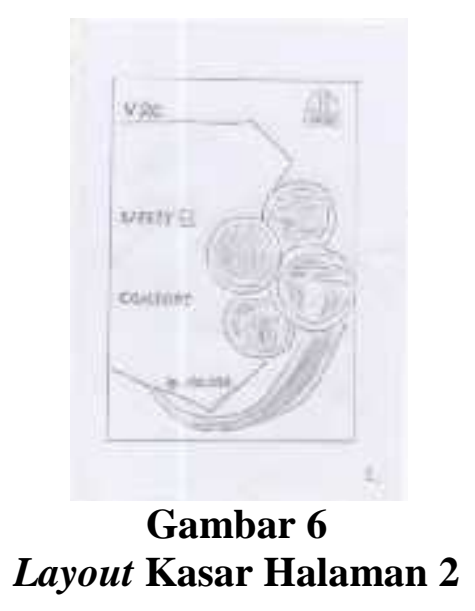

Halaman 2 berisi foto satu brand dari perusahaan yaitu VRC serta menjelaskan keunggulan yang dimiliki salah satu brand perusahaan ini. Font yang digunakan dalam halaman ini adalah Revisal.

\section{Layout Kasar Halaman 3}

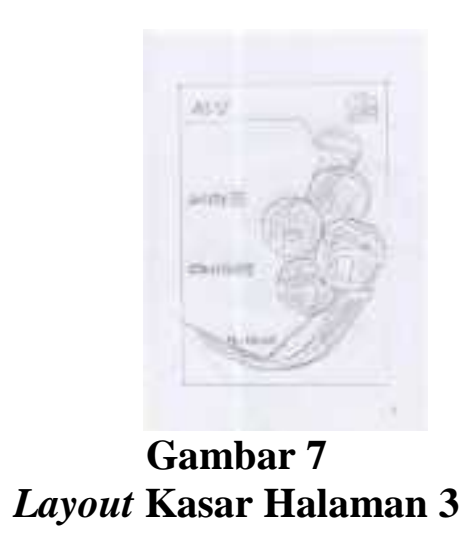


Halaman 3 berisi foto satu brand dari perusahaan yaitu ALV serta menjelaskan keunggulan yang dimiliki salah satu brand perusahaan ini. Font yang digunakan dalam halaman ini adalah Revisal.

\section{Layout Kasar Halaman 4}

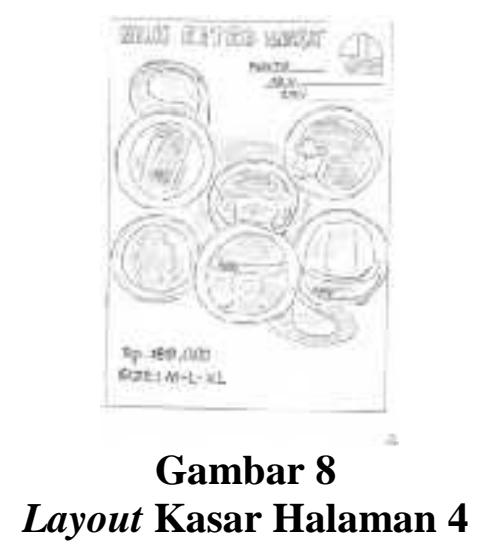

Halaman 4 berisikan seluruh brand yang diproduksi PT. Anugerah Duta Pratama . Font yang digunakan dalam halaman ini adalah Revisal.

\section{Layout Kasar Halaman 5}

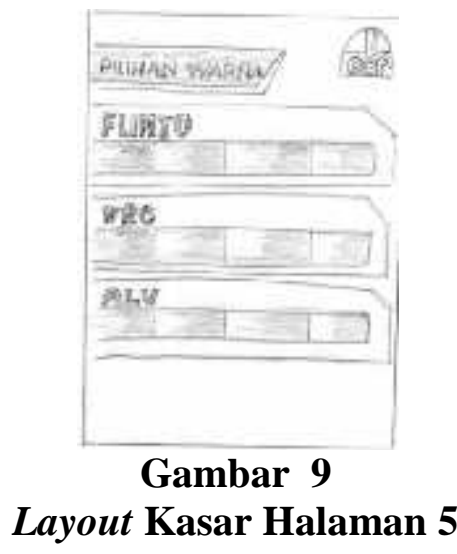

Halaman 5 berisikan pilihan warna helm merek FLINTO, VRC, dan ALV. Font yang digunakan dalam halaman ini adalah Revisal Minion Pro.

\section{Layout Kasar Halaman 6}

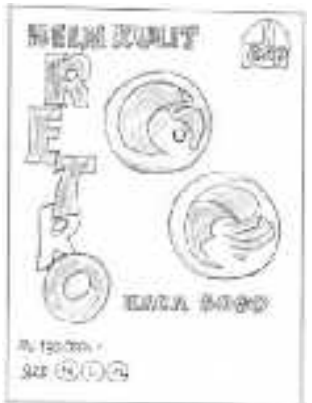

Gambar 10

Layout Kasar Halaman 6 
Halaman 6 berisikan foto produk yaitu Helm Retro Kaca Bogo serta penjelasan tipe warna, size, harga. Font yang digunakan dalam halaman ini adalah Revisal.

\section{Layout Kasar Halaman 7}

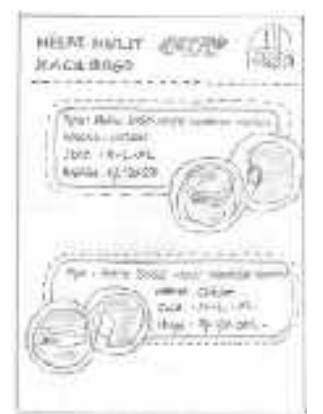

Gambar 11

Layout Kasar Halaman 7

Halaman 7 berisikan foto produk yaitu Helm Retro Kaca Bogo serta penjelasan tipe warna, size, harga. Font yang digunakan dalam halaman ini adalah Revisal dan Helvetica.

\section{Layout Kasar Halaman 8}

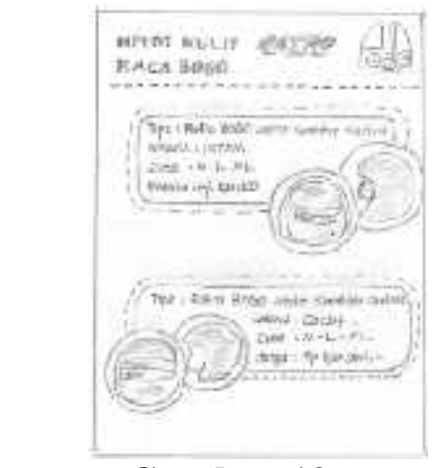

\section{Gambar 12 \\ Layout Kasar Halaman 8}

Halaman 8 berisikan foto produk yaitu Helm Retro Kaca Bogo serta penjelasan tipe warna, size, harga. Font yang digunakan dalam halaman ini adalah Revisal dan Helvetica.

\section{Layout Kasar Halaman 9}

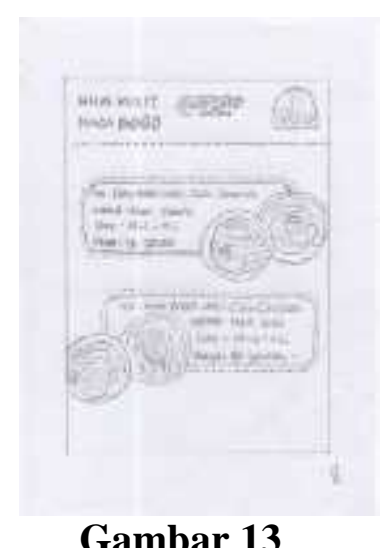

Layout Kasar Halaman 9 
Halaman 9 berisikan foto produk yaitu Helm Retro Kaca Bogo serta penjelasan tipe warna, size, harga. Font yang digunakan dalam halaman ini adalah Revisal dan Helvetica.

\section{Final Artwork}

Final Artwork adalah merupakan gambar kerja final yang telah melewati beberapa proses sebelumnya yaitu layout kasar dan layout komprehensif. Pada proses ini naskah serta tata letak gambar merupakan proses akhir yang siap diproduksi proses cetak atau jenis produksi media secara elektronik setelah disempurnakan dengan beberapa kali revisi selama proses desain.

\section{Final Artwork Cover Depan}

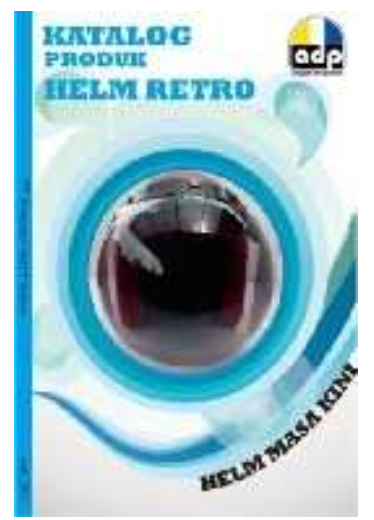

Gambar 14

Final Artwork Cover Depan.

Cover Headline pada promosi ini menggunakan kata : "KATALOG PRODUK HELM RETRO BERGAYA MASA KINI" dengan isi tulisan judulnya berwarna biru sedangkan PT. Anugerah Duta Pratama berwarna hitam. Font yang digunakan pada halaman ini adalah Revisal Bold, Regular, Ultra thin dan hairline.

\section{Final Artwork Daftar Isi}

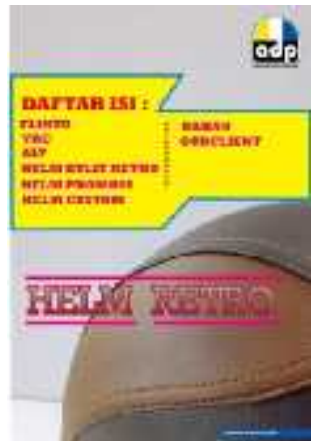

Gambar 15

Final Artwork Daftar Isi.

Halaman daftar isi berisi foto produk dengan tata letak atau layout yang menarik dan font yang digunakan dalam halaman ini adalah Revisal dan Minion Pro. 


\section{Final Artwork Halaman 1}

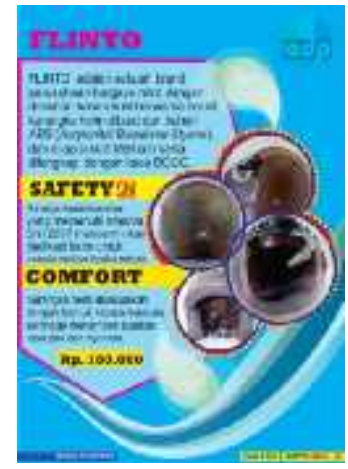

\section{Gambar 16}

\section{Final Artwork Halaman 1}

Halaman 1 berisi foto satu brand dari perusahaan yaitu FLINTO serta menjelaskan keunggulan yang dimiliki salah satu brand perusahaan ini. Font yang digunakan dalam halaman ini adalah Revisal.

\section{Final Artwork Halaman 2}

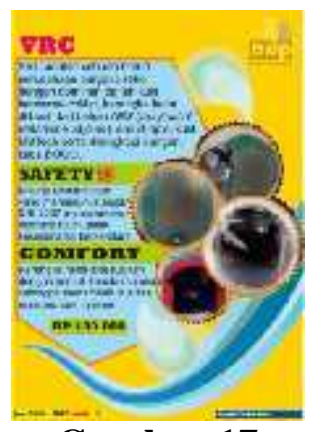

\section{Gambar 17}

\section{Final Artwork Halaman 2}

Halaman 2 berisi foto satu brand dari perusahaan yaitu VRC serta menjelaskan keunggulan yang dimiliki salah satu brand perusahaan ini. Font yang digunakan dalam halaman ini adalah Revisal.

\section{Final Artwork Halaman 3}

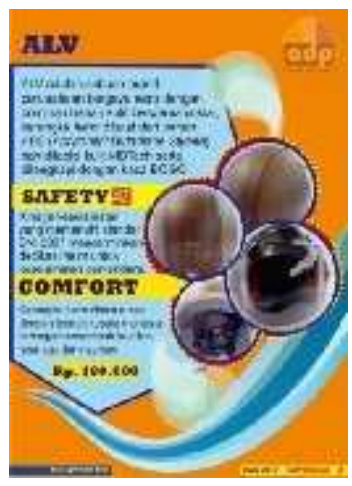

\section{Gambar 18}

Final Artwork Halaman 3 
Halaman 3 berisi foto satu brand dari perusahaan yaitu ALV serta menjelaskan keunggulan yang dimiliki salah satu brand perusahaan ini. Font yang digunakan dalam halaman ini adalah Revisal.

\section{Final Artwork Halaman 4}

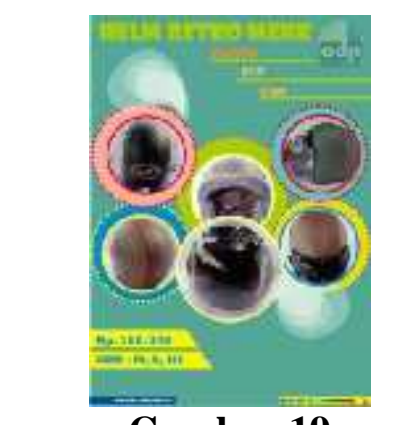

Gambar 19

\section{Final Artwork Halaman 4}

Halaman 4 berisikan seluruh brand yang diproduksi PT. Anugerah Duta Pratama . Font yang digunakan dalam halaman ini adalah Revisal.

\section{Final Artwork Halaman 5}

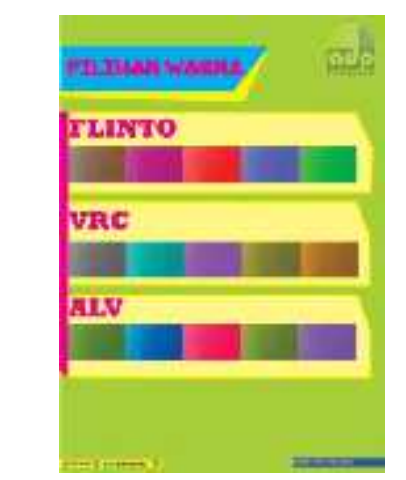

Gambar 20

Final Artwork Halaman 5

Halaman 5 berisikan pilihan warna helm merek FLINTO, VRC, dan ALV. Font yang digunakan dalam halaman ini adalah Revisal Minion Pro.

\section{Final Artwork Halaman 6}

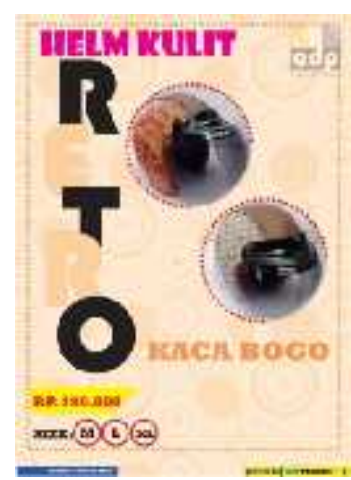

Gambar 21

Final Artwork Halaman 6 
Halaman 6 berisikan foto produk yaitu Helm Retro Kaca Bogo serta penjelasan tipe warna, size, harga. Font yang digunakan dalam halaman ini adalah Revisal.

\section{Final Artwork Halaman 7}

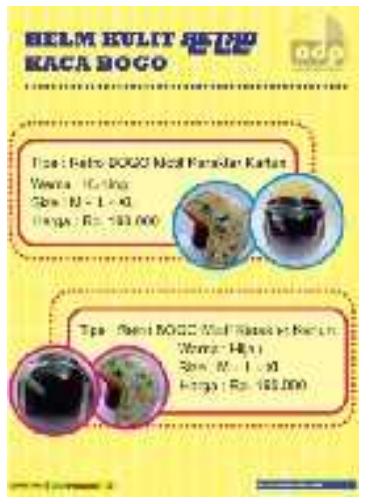

Gambar 22

\section{Final Artwork Halaman 7}

Halaman 7 berisikan foto produk yaitu Helm Retro Kaca Bogo serta penjelasan tipe warna, size, harga. Font yang digunakan dalam halaman ini adalah Revisal dan Helvetica.

\section{Final Artwork Halaman 8}

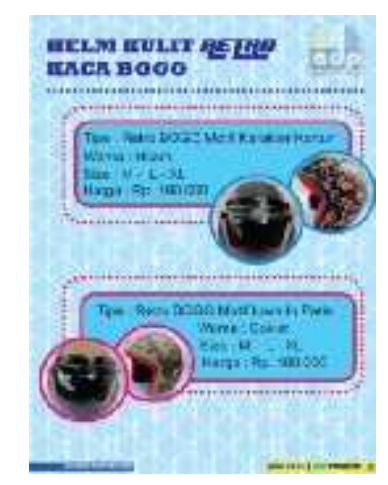

Gambar 23

\section{Final Artwork Halaman 8}

Halaman 8 berisikan foto produk yaitu Helm Retro Kaca Bogo serta penjelasan tipe warna, size, harga. Font yang digunakan dalam halaman ini adalah Revisal dan Helvetica.

\section{Final Artwork Halaman 9}

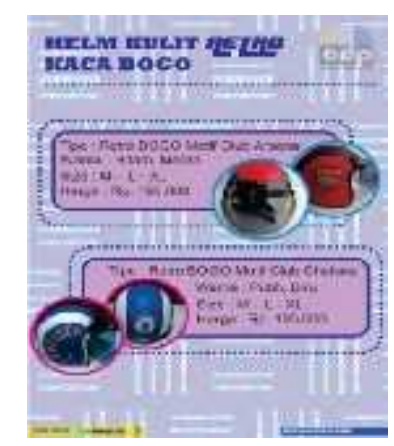

Gambar 24

Final Artwork Halaman 9 
Halaman 9 berisikan foto produk yaitu Helm Retro Kaca Bogo serta penjelasan tipe warna, size, harga. Font yang digunakan dalam halaman ini adalah Revisal dan Helvetica.

\section{Literature Review}

1. Analisis Penerapan E-Catalogue Di Pemerintahan, Jakarta adalah salah satu jurnal yang dibuat oleh Jackson Surianto selaku mahasiswa Universitas Bina Nusantara Jakarta, penelitian ini menjelaskan pembuatan analisis penerapan E-Catalogue yang di pemerintahan jakarta.

2. Pembuatan Katalog Buku Perpustakaan Berbasis Web, Sumatera Selatan adalah salah satu judul jurnal yang di buat oleh Muhamad Kadafi selaku mahasiswa Universitas Indo Global Mandiri, penelitian ini menjelaskan tentang pembuatan katalog buku perpustakaan yang berbasis web.

3. Aplikasi Katalog Islam Berbasis Web Pada Sekolah Tinggi Agama Islam Bakti Negara (Staibn) Tegal, Semarang adalah salah satu judul tugas akhir yang dibuat oleh Widiyono selaku mahasiswa Universitas Dian Nuswantoro Semarang, penelitian ini menjelaskan pembuatan aplikasi katalog islam yang berbasis web yang berada di Sekolah Tinggi Agama Islam Bakti Negara (Staibn) Tegal.

\section{Kesimpulan}

Sebuah media yang dapat dijadikan sebagai penyampaian pesan profil usaha dan sekaligus sebagai media promosi, dengan mempertimbangkan faktor-faktor teknis dan cakupan informasi yang ingin disampaikan media dalam bentuk katalog produk yang dapat mencakup kedua kepentingan tersebut. Dari bentuk media katalog produk tersebut diharapkan dapat memberikan nilai efektifitas dalam penyampaian informasi yang diinginkan.

Corak katalog yang dapat meningkatkan citra suatu perusahaan adalah corak media katalog produk yang bergaya simpel berupa bentuk visual yang komunikatif, efektif, efesien dan tepat sehingga dapat memberikan kesan formal dan ekslusif.

Nilai-nilai efektifitas yang didapatkan dari katalog produk yang dirancang, target yang diinginkan adalah dapat meningkatkan jumlah pesanan helm sesuai target-target yang telah ditetapkan perbulan-pertahunnya oleh perusahaan. Perusahaan manargetkan tingkat penjualan pada tahun 2016 harus meningkat paling sedikit $50 \%$ dari tahun sebelumnya yaitu tahun 2015.

\section{Daftar Pustaka}

[1] Arts, Athenk, 2012. Efek-efek Terbaik CorelDraw dan Photoshop, Penerbit Citra Media Pustaka, Jakarta

[2] Binanto, Iwan, 2010. Multimedia Digital Dasar Teori dan Pengembangannya, Penerbit Andi, Yogyakarta

[3] Budiarto, Mukti, dkk.2011. Desain Media Komuniasi Visual Sebagai Penunjang Kegiatan Promosi Kampus, Journal CCIT Vol.1 No. 2. Tangerang : Perguruan Tinggi Raharja.

[4] Hendratman, Hendi, ST., 2014. Tips $n$ Trix Computer Graphics Design, INFORMATIKA, Bandung,

[5] Ibnu Teguh, Wibowo, 2013. Belajar Desain Grafis, Penerbit Buku Pintar, Yogyakarta,

[6] Komala,Lukiati, 2010. Komunikasi Massa, Jakarta, Universitas Terbuka.

[7] Maimunah dkk, 2012. Jurnal CCIT, Perguruan Tinggi Raharja, Tangerang,

[8] Nasution, Ruslan Efendi. 2012. Implementasi SMS Gateway In The Development Web Based Informasi System Schedule Seminar Thesis. Lampung : Unila. 
[9] O’Brien, 2012. Yakub Pengantar Sistem Informasi, Penerbit Graha Ilmu, Yogyakarta,

[10] Supriyono, Rakhmat. 2010. Desain Komunikasi Visual Teori dan Aplikasi. Yogyakarta: Andi

[11] Sutabri, Tata. 2012. Analisis Sistem Informasi. Yogyakarta : Andi Publisher. 